\title{
PRODUCIR Y GESTIONAR REMESAS POLÍTICAS: EL VOTO TRANSNACIONAL DEL FRENTE AMPLIO DE URUGUAY EN ARGENTINA (1984-2014)*
}

\section{PRODUCING AND MANAGING POLITICAL REMITTANCES: THE TRANSNATIONAL VOTE OF THE FRENTE AMPLIO DE URUGUAY IN ARGENTINA (1984-2014)}

Silvina Merenson**

Resumen: Este artículo describe y analiza la producción, gestión y circulación de remesas politicas, a partir del caso del Frente Amplio de Uruguay en Argentina que, desde la década de 1980, moviliza el voto de los residentes uruguayos en la Argentina hacia el Uruguay ante las elecciones en este último país. Para ello se identifican los actores que integran la red transnacional y las transformaciones operadas sobre su infraestructura material, al mismo tiempo que se observan las especificidades que caben a los procesos de incorporación política en ambos países. El material empírico que sustenta este artículo es producto de la combinación de un trabajo de campo etnográfico multi-situado - que incluye el análisis de fuentes producidas por las y los entrevistados y/o sus agrupaciones políticas - y un trabajo de archivo, que relevó la prensa escrita de ambos países, y de la revisión de fuentes secundarias.

* Agradezco los productivos comentarios realizados en las evaluaciones anónimas de este artículo.

** Investigadora del Centro de Investigaciones Sociales - Consejo Nacional de Investigaciones Científicas y Técnicas/Instituto de Desarrollo Económico y Social (CIS-CONICET/IDES). Profesora Adjunta del Instituto de Altos Estudios Sociales, Universidad Nacional de San Martín (IDAES/UNSAM), Argentina. Correo electrónico: smerenson@unsam.edu.ar 
Palabras clave: migración; prácticas políticas; redes; ciudadanía transnacional.

Abstract: This paper describes and analyzes the production, management and circulation of political remittances by the Frente Amplio de Uruguay in Argentina, which, since the 1980s, has mobilized the vote of Uruguayan residents in Argentina to Uruguay for the elections in the latter country. For that, we identified the actors that integrate the transnational network and the transformations carried out on its material infrastructure. At the same time, we observing the specificities that fit the processes of political incorporation in both countries. The empirical material that underlies this article is a combination of a multi-situated ethnographic fieldwork - which includes the analysis of sources produced by the interviewees and/or their political groups-and an archive work, which the press of both countries, and the revision of secondary sources.

Key words: migration; political practices; networks; transnational citizenship.

\section{INTRODUCCIÓN}

Los criterios de participación electoral, representatividad y legitimidad constituyen algunos de los tópicos más debatidos en los análisis sobre ciudadanía y prácticas políticas transnacionales. Hoy sabemos que los procesos migratorios redefinen las formas de hacer política y de pensar las competencias institucionales, impulsando el análisis crítico de los marcos normativos que intervienen en la definición marshalliana de los derechos cívicos. Las y los transmigrantes no sólo participan en términos procedimentales de las elecciones de su país de origen, también influencian el modo en que otros votan, introducen ideas y estrategias políticas, disputan las agendas de las campañas electorales y proveen o demandan fondos para ellas. Todo ello implica la movilización, a través de las fronteras territoriales, de aprendizajes, experiencias y afectos que nutren la vida política de "aquí" y "allá", en referencia a los países de origen y destino.

Estas dimensiones de las experiencias transnacionales han sido abordadas en términos de "remesas políticas" (Goldring, 2004). 
Este artículo recupera esta categoría para describir y analizar, en perspectiva histórica, la producción, gestión y circulación de este tipo particular de remesas desplegadas por el Frente Amplio de Uruguay en Argentina (FAUA) que, desde la segunda parte de la década de 1980, se ocupa entre otras cuestiones de movilizar el voto de los residentes uruguayos en la Argentina hacia el Uruguay ante los actos electorales en este último país. Estos desplazamientos son conocidos como "voto Buquebus". Vale señalar que Uruguay no cuenta con un mecanismo que habilite el voto desde el exterior, aun cuando éste es obligatorio. La Constitución Nacional no suspende la ciudadanía y, por ende, los residentes en el extranjero conservan su derecho al voto. Quienes residen fuera de las fronteras territoriales del país pueden sufragar, pero siempre y cuando se encuentren en el territorio nacional el día del acto electoral y estén inscriptos en el Registro Cívico².

Aquí nos proponemos explorar las coyunturas asociadas a la creación, consolidación y desestabilización del FAUA, una de las redes políticas transnacionales de mayor densidad en el Cono Sur, fuertemente enraizada en los procesos políticos, económicos y sociales de la región. Para ello, el artículo se organiza en cuatro apartados. El primero presenta algunas de las contribuciones teóricas y referencias metodológicas que, a modo de coordenadas analíticas, nos permitirán abordar —en el segundo acápite- el camino recorrido por el FAUA y - en el tercero- la trama que habilita la producción y gestión del "voto Buquebus", atendiendo a las transformaciones operadas sobre su infraestructura material y canales de circulación, así como a los actores que lo hicieron y/o hacen posible desde hace más de tres décadas. En tanto, en el último apartado, retomamos la literatura reseñada en el primero para formular algunas síntesis, observar las especificidades que caben al caso analizado y sugerir algunas claves analíticas que podrían trascenderlo.

1 "Buquebus" es el nombre de una de las empresas fluviales que une Buenos Aires (Argentina) con Colonia y Montevideo (Uruguay), aquella que emplean mayoritariamente los uruguayos en Buenos Aires para viajar a emitir su voto.

2 Dicha inscripción se pierde en caso de no ejercer el sufragio en dos elecciones nacionales consecutivas y, aunque puede recuperarse, implica un trámite que puede resultar complejo, especialmente para quienes residen en el exterior (véase Taks 2006). 


\section{PERSPECTIVAS TEÓRICAS Y METODOLÓGICAS}

De acuerdo a la definición de Eva Østergaard-Nielsen (2003, p. 762), las prácticas políticas transnacionales abarcan las diversas formas de participación directa en la política del país de origen, así como la participación indirecta en las instancias políticas en el país de acogida, o en distintas organizaciones internacionales. Éstas, en sí mismas, constituyen formas de circulación — con mayor o menor grado de institucionalización- que pueden entenderse como procesos abiertos e inacabados de difusión de ideas, valores y recursos que cruzan las fronteras movilizando compromisos y acciones múltiples, conducidas por distintos actores, tanto migrantes como no-migrantes (Boccagni et al., 2015, p. 445).

Como ya ha sido observado, los vínculos políticos de los y las migrantes con su país de origen no constituyen un tema nuevo de investigación (Portes et al., 2003, entre otros). Así lo indican los distintos análisis sobre las luchas en torno a la obtención o el ejercicio concreto del "voto desde el exterior" por parte de diversos colectivos de migrantes radicados principalmente en los Estados Unidos y Europa (Calderón, 2010; Itzigsohn y Villacrés, 2008; Collyer, 2013; Escobar et al. 2014; Escrivá et al., 2009 y Lafleur, 2012, entre varios otros). A la hora de ponderar las razones o motivaciones de estas prácticas, algunas investigaciones afirman que la referencia para la participación en la vida política del país de origen es el país de residencia (Bauböck, 2003; Waldinger, 2010). Efectivamente, cuestiones como el estatus legal alcanzado en el país de destino, la incorporación al mercado de trabajo y el acceso a servicios básicos parecen operar como bases o plataformas de acción. Sin embargo, la pregunta por los modos en los que se tejen las relaciones institucionales y los vínculos personales que habilitan la incorporación política transnacional requiere de respuestas empíricas que contemplen los contextos históricos y las coyunturas políticas en las que se insertan las prácticas de los actores. Estas respuestas, como es sabido, no pueden contemplar sólo la migración o el desplazamiento de personas, también debe incluir la circulación de ideas, valores y materialidades que impactan sobre los acuerdos y las alianzas que supone la práctica política. Tal como la entiende Goldring (2004, p. 805), la noción de "remesa política", en tanto remesa colectiva no estrictamente monetaria, hace foco en esta amplia heterogeneidad.

¿Quiénes producen y cómo se gestionan remesas políticas? ¿Qué infraestructura material requieren? ¿En qué momentos resultan 
interpeladas y por quiénes? ¿Qué informan respecto de los juegos políticos y las democracias de los países involucrados? Estas son algunas de las preguntas que aquí orientan el análisis de las redes transnacionales frenteamplistas cuyo potencial, vale adelantarlo, está conformado por múltiples inequidades. Estas inequidades se basan, entre otras, en las asimetrías existentes entre los actores migrantes y no-migrantes que integran la red, especialmente en las diferencias asociadas a los valores y el acceso a recursos tanto materiales como simbólicos. Así, a modo de ejemplo, ante las habituales acusaciones o sospechas respecto de la erosión moral y/o cultural de los migrantes derivadas de su socialización en el país de destino, las remesas políticas pueden presentarse como una respuesta - como "un tipo de acción comunicativa" y no como un "mero acto de transferencia" (Lacroix, 2014, p. 665)—que persigue la afirmación de la inscripción comunitaria. En este punto es necesario anticipar que las prácticas políticas transnacionales que exploraremos aquí no son "reactivas" ni están determinadas por las dificultades de incorporación o integración en el país de destino, tal como emerge de otros casos de estudio (Itzigsohn y Saucedo, 2002; Portes y Rumbaut, 1990). Más bien se presentan como el resultado de inserciones múltiples o, incluso, de una "híper-integración" de las y los transmigrantes avocados a la actividad política (Lacroix, 2014, p. 672).

Finalmente, cabe una aclaración respecto de la escala y el carácter transnacional de la red frenteamplista y el voto que ésta produce y gestiona. Si bien aquí nos concentraremos en un nodo de la red, los flujos y prácticas políticas transnacionales del frenteamplismo no se reducen a la Argentina, sino que abarcan otros países, tal como lo demuestran los trabajos de Moraes (2019) y Zeballos (2010) para España y Brasil, respectivamente. De ahí que, en su hechura, el "voto Buquebus" no pueda considerarse un voto estrictamente "binacional" o "transfronterizo", sino como parte de un proceso que lo excede y nos permite reflexionar, entre otras cuestiones, sobre los límites y las localizaciones de la comunidad política (Merenson, 2018).

El material empírico que sustenta este artículo es producto del trabajo de campo etnográfico multi-situado desarrollado en la Argentina y el Uruguay entre los años 2009 y 2015, y retomado en la actualidad. La investigación abarcó la interacción con transmigrantes de nacionalidad uruguaya que sostienen o sostuvieron prácticas políticas transnacionales, llegados a la Argentina entre fines de la década de 1940 y la actualidad. Entre 2009 y 2014 realicé 43 
entrevistas en profundidad y 22 historias de vida de hombres y mujeres pertenecientes a distintas generaciones y clases sociales, en su gran mayoría vinculados al Frente Amplio (FA), radicados en la ciudad de Buenos Aires, su región metropolitana y otras provincias argentinas. A las entrevistas realizadas se suma un gran número de conversaciones e interacciones informales, así como el registro etnográfico de las múltiples y diversas instancias públicas y semi-públicas de reunión que movilizaban a la militancia transnacional tanto en la Argentina como en Uruguay - actos partidarios y electorales, mesas redondas, jornadas electorales, reuniones, asambleas y plenarios- en el transcurso de las dos últimas campañas electorales con vistas a las elecciones presidenciales de 2009 y 2014. En el caso de las últimas elecciones (2014), de agosto a noviembre, me incorporé a la dinámica diaria de uno de los Comités de Base $^{3}$ del FA que funcionaban en Buenos Aires. Los datos etnográficos se conjugan aquí con el análisis de fuentes producidas por las y los entrevistados y/o sus agrupaciones políticas, la revisión de fuentes secundarias y el trabajo de archivo, que relevó la prensa escrita uruguaya y argentina de circulación nacional. Con el objetivo de analizar en perspectiva histórica la producción y gestión del "voto Buquebus", el trabajo de archivo abarcó la consulta de la prensa para las semanas previas y posteriores a cada elección presidencial acontecida entre 1984 y 2014, así como la consulta de la prensa partidaria correspondiente a los tres partidos políticos más importantes del período: el Partido Colorado, el Partido Nacional y el Frente Amplio. En este último caso se privilegió, aunque no de modo excluyente, la prensa y los documentos producidos por los sectores políticos del FA con actuación en la Argentina: Movimiento de Participación Popular, Partido Socialista, Partido Comunista, Frente Líber Seregni y el Grupo Magnolia, Uruguayos Unidos por Constanza Moreira.

\section{PRÁCTICAS Y REDES POLÍTICAS EN (LA) TRANSICIÓN}

Buena parte de quienes a comienzos de la década de 1980 fundaron el FAUA migraron a la Argentina en los años inmediatamente

3 Comité de Base designa las células barriales del FA, dedicadas al trabajo político y social en el territorio. 
anteriores o posteriores ${ }^{4}$ al inicio dela dictadura cívico-militar en Uruguay (1973-1985). Sus diálogos y trayectorias políticas están marcadas, primero, por la efervescencia popular de la "primavera camporista" ${ }^{5}$ y, luego, por el recrudecimiento de la violencia política y la represión que derivó en el golpe de Estado argentino de 1976. Si bien no resultan acertadas las generalizaciones, puede observarse que, para quienes en el Uruguay militaban en fuerzas como el Partido Socialista (PSU) o en el Partido Comunista (PCU), la incorporación a la vida política local siguió canales orgánicos. En tanto, para quienes no integraban partidos políticos, sino que se desempeñaban en frentes como el estudiantil o el sindical, la incorporación a la vida política en la Argentina tomó caminos más sinuosos que los llevaron por comisiones directivas de clubes barriales, cooperadoras escolares u otras instancias organizativas de la sociedad civil. Si bien hoy estos militantes no evocan aquellas experiencias como parte de su trayectoria política, éstas parecen haber sido fundamentales en tanto proveyeron espacios de debate que les permitieron elaborar las primeras lecturas del escenario político local y atravesar la sangrienta dictadura argentina (1976-1983).

Para unos y otros, "entender el peronismo6" o posicionarse ante él fue, quizás, el primero de los desafíos políticos en el país de destino. En todas las entrevistas realizadas a quienes integran la generación

4 En las décadas de 1970 y 1980 la migración uruguaya hacia la Argentina, que representó alrededor de la mitad del volumen total del período, estuvo signada por la represión política que derivó y se mantuvo durante la dictadura militar (1973-1985) y la crisis económica. Desde el siglo XIX, la Argentina es el país en el que vive la mayor parte de los emigrantes que contabiliza el Uruguay. Actualmente concentra cerca del 4,5\% del padrón electoral, unas 116.000 personas según los últimos datos censales (2010), aunque las autoridades consulares afirman que el número real triplica el censal.

5 En marzo de 1973 la victoria electoral de la fórmula Cámpora-Solano Lima puso fin a siete años de dictadura en Argentina. Al frente de la presidencia por 49 días, Cámpora convocó a elecciones sin la proscripción de Juan Domingo Perón, que lo sucedió en la presidencia en octubre de ese mismo año hasta su muerte, el 1 de julio de 1974.

6 Dada la importancia en la vida política argentina del movimiento político encabezado por Juan Domingo Perón (conocido como "peronismo"), éste constituye en sí mismo un campo de estudio desde hace ya varias décadas. Dados los debates académicos que ha suscitado, cualquier intento de síntesis o caracterización, resultaría inevitablemente una simplificación. En su lugar, remito al lector a los trabajos ya clásicos de Murmis y Portantiero (1971) y Halperín Donghi (1994), entre otros posibles. 
fundadora del FAUA está presente una suerte de encuentro fundacional con su militancia que viene a explicar, al menos en parte, las relaciones institucionales y los vínculos personales que fueron construyendo a lo largo de los años, sin los cuales hoy difícilmente pueda comprenderse la red transnacional del FAUA. Por esta razón vale detenerse en algunos de estos relatos que indican cómo, tempranamente, el contexto político en el país de destino permeó las acciones y lecturas de la futura militancia transnacional. Veremos entonces las definiciones y posicionamientos de José $^{7}$ y Juan como síntesis paradigmáticas de muchas otras registradas en el transcurso del trabajo de campo.

José llegó a Buenos Aires con 33 años, casi al mismo tiempo en que Juan Domingo Perón retornaba al país tras su exilio en España, es decir en junio de 1973. Se alojó en una pensión del centro y, según recuerda, "tenía para comer un paquete de galletitas y una banana por día”. Lo que creía sería una estancia breve - "una cuarentena hasta que las cosas se calmen" en Uruguay-, se prolongó hasta el presente. Desde la pensión escuchó "el bullicio" de la ciudad el día en que regresó Perón y decidió sumarse a la multitud. Su presencia allí asume un carácter revelador:

Nunca vi nada igual, niños en las marchas, bombos, cotillón. Mientras caminaba entre toda esa gente, vi una bandera que decía 'Matacos con Perón'. Fue la primera vez en mi vida que vi un indio: ¡y eran peronistas! Ahí dije: 'acá algo hay, esto es muy importante', y entonces me empecé a interesar y a relacionar. Los que nos vinimos en el '73, '74, nos pudimos radicar rápido gracias al peronismo. El que no lo reconozca, está faltando a la verdad ${ }^{8}$. (José, entrevista, 24 de septiembre 2014)

Desde entonces, las relaciones que José trabó con la militancia de la izquierda peronista lo llevaron a participar como periodista en distintas publicaciones desde las cuales cubre, hasta el presente, el acontecer político uruguayo. En cambio, para Juan, uno de los

$7 \quad$ A fin de resguardar el anonimato, los nombres de las y los entrevistados han sido modificados.

8 A comienzos de los setenta, como señalan Porta y Sempol (2006) existía cierta tolerancia respecto de los plazos y documentos a presentar para obtener la radicación. Entre 1973 y 1974 al frente de la Dirección Nacional de Migraciones (Ministerio del Interior) de migraciones estuvo Lelio Mármora, un joven sociólogo integrante de Juventud Universitaria Peronista. Sin embargo, hacia 1975, la situación cambió dramáticamente. 
militantes del PSU integrado al FAUA desde hace unos 10 años, el encuentro con el peronismo está asociado a la violencia política en los años 1970. Ésta, entre otras cuestiones, confirma la lectura que tenía del movimiento peronista antes de llegar a Buenos Aires, cuando vivía en la ciudad uruguaya de Paysandú, trabajaba como operario de una fábrica y, si bien era frenteamplista, no militaba en la coalición:

Yo era gorila [antiperonista] allá [en Paysandú] y seguí siendo gorila acá [en Buenos Aires]. En la semana que llegué [agosto de 1975] andaba por Once', caminando, y veo un ómnibus todo prendido fuego. Lo habían prendido fuego los Montoneros ${ }^{10}$, le tiraron una bomba molotov. Nunca me voy a olvidar de eso. Gente de trabajo era... A mí con eso me quedó claro que no tenía nada que ver con lo que era la política para mí. Yo con esa gente no quería saber nada. (Juan, entrevista, 15 de octubre 2011)

De diversas formas, las interpretaciones del peronismo que proponen José y Juan ofrecen intentos de acoplar los posicionamientos que sostenían en Uruguay con los que comenzaban a asumir en la Argentina o, por el contrario, de argumentar las continuidades en sus lecturas. Tal como veremos más adelante estas interpretaciones variaron, especialmente en la última década, marcada por los conflictos que enfrentaron a las gestiones de gobierno de ambos países ${ }^{11}$.

La década de 1980 se inauguró con tres acontecimientos que obraron vertiginosamente sobre la organización de la migración política uruguaya asentada en la Argentina: el resultado del plebiscito de 1980 y las elecciones internas de 1982 en Uruguay, y la "guerra de Malvinas”, también 1982 en la Argentina. Entre estos hechos, que fueron leídos como muestras del principio del fin de las dictaduras en ambos países, ocurrió el reencuentro en la Asociación de Residentes Orientales José Artigas (AROJA) y, luego, la creación formal del FAUA. De AROJA, uno de los espacios de solidaridad uruguaya con el pueblo argentino durante el conflicto bélico por Malvinas, surgieron algunos

9 Barrio céntrico de Buenos Aires.

10 "Montoneros" es el nombre de la que fuera la organización revolucionaria más importante dentro de la izquierda peronista de los años 1970.

11 Si bien el diferendo por la instalación de las pasteras sobre el río Uruguay es el más conocido y resonante, no fue el único conflicto bilateral del período. A éste se suma el motivado por el dragado del Río de la Plata y las tensiones surgidas de las diferencias cambiarias y las políticas monetarias; también de las posiciones divergentes en torno al Mercosur y la Unasur en el contexto regional. 
de los Comités de Base que en 1984 confluyeron en la creación del FAUA. Sus lugares de reunión —unidades básicas peronistas, locales sindicales, del Partido Comunista (PCA), el Partido Socialista (PSA) y el Partido Intransigente (PI) — expresaban la infraestructura material provista por el proceso de recomposición de la trama partidaria y sindical argentina, así como los diálogos forjados por la incipiente militancia frenteamplista en el país. Estos espacios, gestionados a partir de vínculos personales, familiares y/o vecinales no son un dato menor. Además de compartir los gastos de mantenimiento y los órganos de prensa, de brindar apoyo y asistencia a las actividades organizadas, muchos de "los compatriotas" que llegaban a los comités eran invitados por la militancia argentina. Tal como recordaba Pedro, integrante de la primera Mesa Política del FAUA:

Nosotros, en Quilmes ${ }^{12}$, armamos dos comités de base. Uno funcionaba en un local de la UOM [Unión Obrera Metalúrgica] y otro en un local del PI. Los compañeros nos daban una mano grande, porque corrían la voz de que nosotros nos reuníamos ahí, lo ponían en los boletines. Si conocían a algún uruguayo del trabajo, del barrio, de donde sea, lo invitaban a que se pase [se sume]. Así era cuando no había Facebook [risas]. (Pedro, entrevista, 23 de agosto 2013)

En algunos casos los vínculos personales derivaron en relaciones institucionales; en otros, en cambio, las relaciones institucionales fueron motivo de conflictos personales, deserciones o migraciones de un comité de base a otro. Luego volveremos sobre esto, ahora lo que deseamos señalar es que la infraestructura transnacional al momento de la fundación del FAUA, aquella que permitirá la circulación de remesas políticas fue, principalmente, obra de los vínculos trabados por su militancia de base. Ésta acompasó la recomposición político-institucional en el Uruguay: tal es el caso de la militancia del PCU que, entre 1981 y 1982, abrió su local en Buenos Aires, en el barrio de Almagro. En "la Sierrita", nombre que remitía a la calle en que se encontraba la sede central del PCU en Montevideo, se planificó uno de los primeros actos de este partido en Buenos Aires que, según sus organizadores, reunió unos 400 compatriotas y contó con la ayuda financiera de un banco argentino estrechamente vinculado al PCA.

12 Ciudad situada en el sur del conurbano bonaerense. 
En diciembre de 1983, luego de siete años de dictadura, Raúl Alfonsín asumió la presidencia argentina y Buenos Aires volvió a ser base del frenteamplismo disperso por el mundo ${ }^{13}$. Pocos meses después, el FAUA contaba con un local propio en el centro de la ciudad financiado por la militancia local, reproducía la estructura que se había dado desde su fundación en el Uruguay y nucleaba a más de 30 comités de base situados en distintos barrios de la capital, ciudades del conurbano bonaerense y del interior del país. Además de la reunión plenaria, su militancia sostenía tres reuniones semanales que, según sintetizaba Ignacio, "se vivían como una fiesta de cumpleaños. Era una alegría inmensa, de repente te encontrabas con gente que ni sabías que estaba viviendo acá [en Argentina]. En cada reunión, éramos más" (Ignacio, entrevista, 19 de mayo 2012).

La participación del FAUA en la lucha contra la dictadura uruguaya fue sumamente intensa, aunque breve ${ }^{14}$. Más bien su actividad se concentró en la recepción de las y los exiliados que iban aproximándose al regreso al Uruguay y en la estabilización de la coalición en Argentina. Aun cuando el retorno era el objetivo de muchos - y el FAUA se hizo eco de ello incorporándolo a su plan de acción de $1986^{15}$-, no era un objetivo realizable por todos, especialmente por quienes habían construido sus familias en Argentina; o por quienes habían logrado una incorporación satisfactoria al mercado de trabajo que, al menos por el momento, no veían posible reproducir en el Uruguay pos dictatorial.

13 Como se desprende del libro de Aguirre Bayley (2007), hasta entonces el FA en el Exterior había concentrado sus actividades en otros destinos del exilio, principalmente en México, la URSS y distintos países europeos.

14 Entre fines de 1982 y hasta 1985 se realizaron en la Argentina distintos actos, recitales y conferencias de prensa que tuvieron gran repercusión en ambos países. Entre ellos se destacan el recital en el que se presentaron los músicos Daniel Viglietti y Alfredo Zitarrosa; la concentración convocada el 27 de junio de 1984, día en que se cumplieron 11 años de la dictadura uruguaya, que contó con la concurrencia de unas 5.000 personas en Buenos Aires y se repitió en otras ciudades del país; la concentración que celebró la liberación de Líber Seregni (19-3-1984), la que una semana después celebró el 13er aniversario del primer acto público del FA (26-3-1984) y la concentración que recibió a Seregni en su primera visita a Buenos Aires tras su liberación (25-9-1984).

15 El FAUA tomó parte de la "Comisión del Reencuentro", una instancia multipartidaria a la que consideró "un ámbito privilegiado para desarrollar esa gran tarea que es organizar el retorno” (La Hora Frentista 22/3/1986). 
El FAUA colaboró en el retorno de su militancia y aportó a los costos financieros que implicó reinstalar el FA en Uruguay (La Hora Frentista, 22/3/1986), pero también buscó capitalizar los múltiples contactos con el amplio arco político argentino atento a la transición democrática uruguaya. La recuperación y consolidación de las democracias en la región como un valor compartido por la dirigencia política de ambos países, indicó al FAUA la heterogeneidad de sus vínculos locales, cuestión que desde entonces pasó a ser fuente de su fortaleza, pero también de sus conflictos internos. Al apoyo de senadores, diputados y referentes de las organizaciones de Derechos Humanos argentinas, los relatos de los integrantes de la generación fundadora del FAUA suman funcionarios de gobierno y políticos clave de la transición local, quienes allanaron la regularización de la situación migratoria de varios compatriotas, facilitaron el otorgamiento de subsidios para impulsar emprendimientos sociales, culturales y comunicacionales y colaboraron en la campaña financiera con vistas a las elecciones de 1984, aquellas que pondrían fin a la dictadura uruguaya. Desde entonces, esta heterogénea red de relaciones institucionales y personales vincula a referentes sociales y políticos argentinos con la militancia del FAUA y la dirigencia montevideana del FA. Se trata de relaciones que, si bien se intensifican en tiempos electorales, hacen posible la sustentabilidad del FAUA.

Si el FAUA debía concentrarse en "juntar votos" o, en cambio, debía dedicarse a conformar una agenda política propia, que pudiese intervenir en el programa de la coalición, fue una discusión que dominó por entonces los debates. Tomando por base el territorio nacional, partiendo de las diferencias entre lo que implicaría ser militante dentro y fuera del país, estaban quienes consideraban que el FAUA debía seguir la agenda del FA, volviendo a los procesos electorales - es decir a las instancias definitorias de la democracia procedimental- el eje central de su tarea política. Otros, en tanto, entendían que la participación activa en el proceso de toma de decisiones $-\mathrm{y}$ con ello en las instancias provistas por la democracia sustantiva - tenía como fundamento una amplia e intensa trayectoria de compromiso con el país, enriquecida además por otras experiencias políticas y por una lectura del orden regional que, desde afuera, podían fortalecer al FA.

De lo sintetizado hasta aquí puede desprenderse que, en la segunda parte de la década de 1980, el FAUA experimentó una 
doble transición política: aquella asociada a la experiencia de la recuperación democrática en ambos países; y aquella que, descartada la decisión de retornar al Uruguay de buena parte de sus integrantes, comenzaba a mostrar que el FAUA había llegado para quedarse, dando lugar a una militancia transnacional de carácter permanente que, entre otras cuestiones, asumió el desafío de movilizar el voto frenteamplista radicado en la Argentina, su remesa política más importante.

\section{EL "VOTO BUQUEBUS": DEL ARTESANADO A LA INSTITUCIONALIZACIÓN}

Lo que hoy conocemos como "voto Buquebus" comenzó para el FAUA con las elecciones presidenciales de 1984 y fue afianzándose al compás del trabajo y los diálogos sostenidos con la militancia en la Argentina, así como por la consolidación del FA como fuerza electoral en el Uruguay. Desde entonces, la organización del voto frenteamplista radicado en diferentes partes del país es una tarea colectiva que procura y define distintas interlocuciones y alianzas, el involucramiento del potencial electorado — que no siempre fue a votar del mismo modo o por las mismas razones- y las representaciones existentes sobre él en Uruguay.

En líneas generales, las dos primeras elecciones presidenciales tras el fin de la dictadura —las de 1984 y $1989^{16}$ — estuvieron dominadas por la expectativa del retorno a la vida política y democrática y, en algunos casos, por el deseo de volver a radicarse en el país; también por los "errores" que hoy la militancia del FAUA atribuye a la falta de experiencia en la organización de los "viajes electorales". En estas primeras ocasiones, con la contribución financiera de militantes y adherentes, se alquilaron ómnibus que arribaron mayoritariamente a Montevideo

16 Las elecciones generales de 1984 se llevaron a cabo el 25 de noviembre, votó casi el 88\% del padrón (integrado por 2.197.503 ciudadanos). Se impuso el candidato del PC (Julio María Sanguinetti), con el 41\% de los votos. El Partido Nacional obtuvo 35\% y, el FA, el 21\%. En tanto, en las elecciones del 26 de noviembre de 1989, resultó electo Luis Alberto Lacalle (PN), con 38\% de los votos, sobre un padrón de compuesto por 2.319.022 ciudadanos y una participación del $88,6 \%$. El PC obtuvo en esta ocasión el 30\% de los votos y, el FA, el 21\%. 
por los pasos fronterizos del litoral, también se confeccionó un listado de personas que viajarían en vehículos particulares y contaban con lugares disponibles para trasladar votantes. El "boca en boca", las audiciones radiales de la colectividad, las cadenas de llamados telefónicos, el envío de telegramas, las mesas de información en las principales plazas y espacios públicos, así como las pegatinas o pintadas - realizadas con el apoyo de la militancia argentina - fueron los principales canales de difusión de la campaña frenteamplista en Argentina. En esta coyuntura, si bien el FAUA mantenía una comunicación fluida con el FA a través de su Comisión de Asuntos y Relaciones Internacionales, estos viajes electorales no contaron con financiamiento institucional, más bien fueron posibles gracias al sustento material provisto por la red política local construida "desde abajo", a partir de las implicaciones e identificaciones de las y los transmigrantes con algunos partidos políticos argentinos que colaboraban aportando sus estructuras y el trabajo de sus bases. Las cadenas de contactos, recordaba Blanca, se gestaban generalmente en Uruguay:

compañeros de allá [Uruguay] decían 'tengo una prima en Buenos Aires' o 'mi tío vive en Ituzaingó', y nos pasaban la dirección o el teléfono. Nosotros los contactábamos para hacerle llegar la plataforma y los invitábamos a viajar juntos. También buscábamos a los compañeros que eran artistas famosos acá para que nos ayuden a difundir. Me acuerdo que yo, un día, me fui hasta ATC [el canal de la televisión pública argentina] y me quedé en la puerta esperando a que salga [uno de los ex integrantes de Telecataplúm, un programa humorístico], que estaba viviendo acá, para que firme nuestra convocatoria. Era más o menos así, artesanal, la cosa. (Blanca, entrevista, 10 de noviembre, 2014)

Las y los organizadores de estos primeros viajes recuerdan particularmente las dificultades que encontraron al llegar a frontera. Además del atiborramiento de los pasos internacionales que los demoró por horas, cuestión que se repitió en otras ocasiones electorales, estas primeras elecciones estuvieron teñidas por una serie de denuncias sobre estafas, intentos de frenar la caravana de vehículos y pedidos de sobornos para permitir su marcha. Estos hechos, que por entonces llegaron a la prensa montevideana, fueron decodificados como parte de la contienda política.

Las conflictivas escenas situadas en la frontera, relatadas por quienes participaron de estos viajes, se contrapesan con el hondo 
sentido emotivo descrito para la recepción que encontraron al llegar y las gestiones estatales realizadas para facilitar el traslado. En este último punto, quienes participaron de estos viajes evocan el decreto presidencial por el cual en 1989 el gobierno argentino otorgó licencia con goce de sueldo a los ciudadanos uruguayos en condiciones viajar a votar - una medida que, entre otras, se reiteró ante cada jornada electoral, incorporando así determinadas prácticas de Estado ${ }^{17}$ a la red transnacional- y el bullicioso recibimiento de la caravana que sumaba más de 300 autobuses especialmente rentados para el traslado. La prensa también se ocupó de registrarlo: por aquellos días varias notas y editoriales dieron cuenta del arribo de las y los votantes entre el compromiso y la épica. La idea de estar cumpliendo con un deber cívico, la responsabilidad ${ }^{18}$ con que lo hicieron y el esfuerzo que ello supuso se combina en las notas con la descripción de escenas sumamente emotivas, como la entonación del himno nacional por parte de las y los sufragantes al pisar suelo uruguayo (El País 26/11/1984) o el hecho de dormir en plazas y espacios públicos a la espera de poder votar (El País 27/11/1989). A ello se suma un dato no menor dadas las transformaciones posteriores operadas sobre la percepción de este voto transnacional: la valoración positiva del rol desempeñado por todos los partidos políticos uruguayos organizados en la Argentina en tanto "facilitadores" de la "gesta cívica" que protagonizaron miles de compatriotas (El País 27/11/1989).

Como otros y otras protagonistas de aquellos viajes, Richard destacaba algunos de los rasgos que la generación fundadora del FAUA atribuye hoy al electorado que movilizaba en los años 1980: “a mí me parece que era como más homogéneo. Éramos los que nos habíamos exiliado, mal que mal todos teníamos una militancia y estábamos muy al tanto de lo que pasaba en Uruguay a nivel político" (Richard, entrevista, 24 de octubre, 2013). En tanto Ana, tomando como punto de comparación las elecciones de 2004, aquellas que dieron la primera victoria electoral al FA en una

17 Al decreto presidencial mencionado se agregaba la eliminación de la confección de formularios migratorios para ingresar al país y del pago de peajes por el tránsito en los puentes internacionales.

18 A modo de ejemplo, el diario El País señalaba: "no se puede descartar el porcentaje de uruguayos residentes en el exterior que al momento de llegar a Montevideo se mostraron o identificaron con los indecisos (...) por dicho motivo optaron por llegar en los tres primeros días de la semana pasada" a fin de informarse (El País 27/11/1989). 
elección presidencial, señalaba: “capaz que éramos menos, no había las formas de comunicarse que tenés ahora, ni teníamos el nivel de organización que tenemos ahora. Pero creo que sentíamos la política uruguaya más cerca (...), creo que antes la gente viajaba [a votar] más informada que ahora" (Ana, entrevista, 27 de noviembre, 2015). Vale apuntar que esta sensación relativa a una suerte de voto transnacional masificado, más accesible a los y las compatriotas dados los diversos recursos con los que hoy cuenta la militancia frenteamplista, es compartida por varios integrantes de esta generación. Pero no sólo estas comparaciones establecen las diferencias entre aquellas elecciones de los años 1980 y las desarrolladas tas la victoria de 2004: los resultados, "la vuelta con la derrota en mano", también ingresa en los relatos como condensaciones de sentidos de estos primeros procesos electorales transnacionales. Gastón, por ejemplo, evocaba estos viajes a partir de la intersección de las trayectorias migratorias, las memorias del terrorismo de Estado, el ejercicio de la ciudadanía y las reglas del juego electoral:

las vueltas [a la Argentina] eran terribles, tristísimas. Me parece que era [así] porque se mezclaba todo. Venías de unos días de estar con tus amigos de toda la vida, con tu familia, de estar en tu barrio, que asado de acá y asado de allá; de vivir el día de las elecciones, de esperar los resultados... de todo eso. Y en un par de días pasabas a volver [a Buenos Aires], y no era fácil porque además de la nostalgia volvíamos habiendo perdido, con toda la historia encima, ¿no? Los compañeros asesinados, los desaparecidos (...) terrible para nosotros que éramos exiliados. Me acuerdo de las broncas en el viaje de vuelta (...) compañeros que decían 'no vengo más [a votar]' y, después, llegaban de nuevo las elecciones y ahí estaban, repartiendo volantes. Esas cosas pasaban, eran muchas emociones mezcladas. (Gastón, entrevista, 13 de abril 2013)

Los procesos electorales ocurridos en la década de 1980 inauguraron un circuito de ideas, valores, dinero, personas y sufragios que el frenteamplismo en la Argentina supo sostener y actualizar hasta el presente. En un comienzo, el deseo del retorno al Uruguay, pero también la defensa y consolidación de las democracias recuperadas en ambos países definió acciones y compromisos múltiples, tanto de personas de migrantes como no migrantes. La solidaridad entre la militancia de base, tramada en diversos espacios 
sociales y políticos de interacción, guio las relaciones institucionales que fueron fortaleciéndose o debilitándose con el correr de los años, en sintonía con la maduración del FA como alternativa electoral y las conflictivas relaciones bilaterales entre los gobiernos de Argentina y Uruguay.

Para comienzos de este siglo, la organización de las campañas políticas y los viajes electorales se modificaron sustantivamente. Luego de la crítica y paradójica década de $1990^{19}$, el frenteamplismo en la Argentina vio incrementar su caudal de militantes. Como correlato del flujo migratorio asociado al ciclo neoliberal uruguayo, el FAUA se nutrió con el arribo de nuevos compañeros, aquellos que en algunos casos se definen como "exiliados económicos". Rosa, quien integra este grupo, describía como sigue esta incorporación:

ninguno se quiso ir del Uruguay, nos hemos ido por causas políticas o por causas económicas, que también son políticas. Porque los que nos vinimos en los noventa, somos exiliados de los gobiernos de hambre, y no es que nos vinimos a llenarnos de plata y a pasarla bomba [muy bien], iporque Argentina tampoco era Disney! (Rosa, entrevista 25 de abril, 2018)

El encuentro entre exiliados/migrantes "políticos" y "económicos" no fue una tarea sencilla, pero contribuyó a actualizar la mirada sobre la situación del país y las posibilidades electorales de la coalición y, con el tiempo, también renovó algunos liderazgos. Además, ayudó a atemperar las confrontaciones ideológicas que caracterizaba a la vieja guardia del FAUA. Algunos comités de base retomaron sus actividades o se crearon nuevos, aunque por lo general fueron desprendimientos de los ya existentes. Tal es el caso de "Volveremos", uno de los primeros comité de base creado en los años 1980, que reinició sus actividades como "Comité Palermo" en 2009, reuniendo a parte de la militancia del primero. Acorde al proceso en el Uruguay, algunos sectores políticos integrados a la coalición ganaron peso en detrimento de otros. A modo de ejemplo, en Buenos Aires fue evidente la consolidación del Movimiento de

19 Por razones de espacio no nos detenernos aquí en los viajes electorales desarrollados en este periodo, en que el neoliberalismo atravesó dramáticamente las actividades de las organizaciones sociales y políticas en ambos países pero, al mismo tiempo y dada la diferencia cambiaria, el FAUA se convirtió en un destacado nodo financiador de la coalición. 
Participación Popular (MPP) ${ }^{20}$ y de Asamblea Uruguay, así como la creación de nuevos sectores, como "Uruguayos en Argentina con Constanza" Moreira. Lo mencionado indicaría que, al menos para este caso y tal como hemos visto hasta aquí, aun cuando el país de destino oficia como referencia y sostén material en la incorporación a la vida política del país de origen, la línea política sigue muy de cerca los pasos y tiempos señalados por este último.

El paulatino proceso de heterogeneización tanto de las trayectorias políticas como de las generaciones migratorias reunidas en el FAUA fue de la mano, aunque no sin conflictos, de los reordenamientos del escenario político argentino, especialmente de la consolidación del kirchnerismo ${ }^{21}$ y la agudización de los conflictos bilaterales entre los países. Ambas cuestiones, lejos de operar como telón de fondo, tuvieron un rol central en la red que sostenía el voto transnacional frenteamplista, cuyas motivaciones y representaciones también se modificaron. Concretamente, la participación electoral como antesala del retorno al Uruguay dejó de ser parte del horizonte argumentativo de las y los sufragantes para pasar a ser entendido, primero, como una contribución al arribo del FA al Poder Ejecutivo por primera vez en su historia política y, luego de ello, como una apuesta a la consolidación de un "modelo de país" que entienden positivo, tanto para sus familiares y amigos en el Uruguay como para la diáspora que integran. Esto último no es menor, pues incluye un posicionamiento electoral respecto de: la política exterior que esperan del Uruguay, sus programas de vinculación extraterritorial y la composición y función del cuerpo diplomático en Argentina. No se trata entonces de un voto que pondera sólo el bienestar de terceros, también es un voto que las y los involucra considerablemente en tanto ciudadanos radicados en el exterior, por el que además esperan una retribución que asegure gobernabilidad y beneficios para la diáspora. A diferencia de otros casos basados en trayectorias migratorias que tienen por destino países del Norte, el ejercicio de este voto no se presenta acompañado de un reclamo de reconocimiento formal o

20 Vale mencionar que, en lo reciente, su candidato a delegado regional a la mesa política del FA obtuvo la mayoría de los votos, quebrando así 30 años de representantes alineados con el PCU.

21 De este modo se designa al movimiento político argentino de orientación peronista que inaugura el gobierno de Néstor Kirchner (2003-2007) y continúa su esposa, Cristina Fernández de Kirchner (2007-2015) en dos mandatos presidenciales. 
simbólico situado más allá de la participación política real de los migrantes ${ }^{22}$; tampoco bajo una lógica económica sostenida en las remesas monetarias, cuya magnitud en este caso es sumamente escasa tanto en términos absolutos como en relación a diversos agregados macroeconómicos ${ }^{23}$.

Tras la victoria del FA en las elecciones presidenciales de $2004^{24}$, aquellas en las que el "voto Buquebus" encontró su consagración pública, pues distintos medios de comunicación y analistas políticos atribuyeron el escaso margen electoral del triunfo en primera vuelta a "los votos llegados desde la Argentina"25, la infraestructura y los canales de circulación que hasta entonces hacían posible los artesanales viajes electorales, inició un sostenido proceso de institucionalización. En ocasión de las siguientes elecciones nacionales, las de $2009^{26}$, aquellas que llevaron a la presidencia a José Mujica, la mediación del FA en la organización del voto transnacional se nutrió de la inédita y desafiante campaña denominada "voto amigo", aquella que buscó desindividualizar el voto para multiplicarlo. Como ya describimos y analizamos en otra

22 Algunas investigaciones han destacado la importancia que adquiere para distintos colectivos de migrantes radicados en Estados Unidos o en países europeos el envío de remesas monetarias a la hora de demandar - u otorgar, en el caso de los Estados- el derecho al voto extraterritorial. También han apuntado que el reclamo del voto extraterritorial persigue un sentido de reconocimiento formal o simbólico, más allá de la voluntad de participación política real. Ello explicaría uno de los tópicos recurrentes en la literatura: el bajo nivel de participación de los migrantes en los actos electorales de sus países de origen. Al respecto, entre otros, véase Calderón Chelius (2010), Itzigsohn-Villacrés (2008).

23 Según indica el informe de la Organización Internacional para las Migraciones de 2011, desde hace al menos diez años las remesas monetarias no llegan a representar el $2 \%$ del PBI uruguayo.

24 Las elecciones de 2004 se realizaron el 31 de octubre. Participó de ella casi el $90 \%$ del padrón, integrado por 2.488 .004 ciudadanos. Se impuso la fórmula del FA (50,4\%). En tanto, el PN obtuvo $35,1 \%$ y, el PC, el 10,6\%.

25 Si bien esta lectura es un debate en sí mismo, lo que nos interesa señalar es que, como tal, se instaló con gran fuerza en la opinión pública, modificando con ello la (auto)percepción que hasta entonces circulaba sobre la militancia trasnacional frenteamplista, tanto en Uruguay como en Argentina.

26 Las elecciones de 2009 se realizaron el 25 de octubre (primera vuelta) y el 29 de noviembre (segunda vuelta). En la primera vuelta participó el 89.85\% del padrón, integrado por 2.563.397 ciudadanos. Se impuso el FA (47.96\%), seguido por el PN (29.07\%) y el PC (17.02\%). La segunda vuelta, con una participación del $89.13 \%$, consagró al FA (54.63\%) sobre el PN (45.37\%). 
ocasión (Merenson, 2015), esta campaña invitó a los frenteamplistas radicados en países distantes (en Europa y Estados Unidos), que tenían pensado viajar al Uruguay para votar, a donar el dinero de sus pasajes para comprar los de quienes residen en la Argentina. La propuesta se basó en un cálculo simple: con el costo del pasaje de un votante frenteamplista residente en un país lejano, podía financiarse varios pasajes de votantes frenteamplistas residentes en Argentina. Sin importar entonces quien lo depositara en la urna, el "voto amigo", vía el "voto Buquebus", era un voto del FA para el FA que contribuiría a ganar las elecciones por segunda vez consecutiva. Desde la perspectiva del FAUA, y más allá de su viabilidad, esta innovación electoral era vista como una "consecuencia lógica" de la solidaridad y el histórico compromiso de la izquierda uruguaya, pero también como una muestra de la densidad que había alcanzado su red política y del esfuerzo depositado por años en los desplazamientos electorales a través de las fronteras territoriales. Ambas cuestiones, según Blanca, hacían del "voto Buquebus" un "voto único", "sustantivamente democrático", contrario al espíritu liberal que ve en él la máxima instancia de expresión y de participación cívica del ciudadano en tanto individuo.

El protagonismo ganado por el "voto Buquebus" en las elecciones de 2004 derivó en el incremento del poder de negociación del FAUA al interior del FA. Esto fue particularmente visible en algunos de los sectores que integran la coalición. Por ejemplo, el MPP pasó a considerar a la Argentina una departamental más, en pie de igualdad con las que funcionan en territorio uruguayo, con su consecuente representación en las instancias resolutivas de este sector político. Estos cambios, entre otras cuestiones, operaron sobre las lecturas que pueden hallarse en parte de la prensa uruguaya. Como veremos, algunos medios de la prensa escrita dejaron de subrayar y elogiar la "gesta cívica" o el rol desempeñado por la militancia transnacional para pasar a denunciar su entramado en términos de "corrupción" o "intromisión" del gobierno y los políticos argentinos en los asuntos internos de Uruguay, en el marco de una creciente oposición a las iniciativas de reglamentación del voto a distancia promovidas por el $\mathrm{FA}^{27}$.

Tras ocho años en el poder, para las últimas elecciones presidenciales (2014), el FA avanzó en la institucionalización del

27 Para un análisis de las distintas iniciativas que en el período buscaron habilitar el voto extraterritorial véase Stuhldreher (2013) y Crosa (2010). 
"voto Buquebus". Para ello creó dentro de su organigrama una comisión ${ }^{28}$ encargada de la negociación de los pasajes con distintas empresas de transporte, la supervisión logística de los viajes y el control de la entrega de los vouchers a las y los votantes ${ }^{29}$. La absorción institucional del traslado del voto frenteamplista residente en Argentina redefinió tareas y roles del FAUA, al mismo tiempo que puso en evidencia lecturas dispares, incluso contradictorias, respecto de la "necesidad" o de "los problemas" que acarreaba el apoyo a la movilización de este electorado. Dicho en otros términos: la decisión de la dirigencia del FA de dejar en manos de militantes especialmente "llegados desde Montevideo" la entrega de pasajes buscó, entre otras cuestiones, neutralizar posibles prácticas discrecionales o clientelares atribuidas a su militancia en Buenos Aires. Vale señalar que parte de la dirigencia montevideana del FA interpreta estas prácticas como ejemplo de la "peronización" de su militancia local: esto es, como "vicios" adquiridos en la participación de la vida política argentina. Sin embargo, este tipo de imputaciones morales que impulsan asimetrías e inequidades tramadas en la red, también registra algunas de las estrategias que permiten nutrir de votantes a los viajes electorales. Dicho en otras palabras: los viajes electorales dinamizados por la militancia frenteamplista en la Argentina se nutren de sufragios gracias a las campañas electorales, pero también, y aun cuando puede ser estigmatizada, de la participación de la militancia en los programas estatales argentinos y de la reciprocidad política entablada con intendentes locales (Merenson, 2013). En consecuencia, los comités de base pasaron a ser espacios en los que difundir información, contactar y recibir consultas del potencial electorado, mientras que la dirigencia del FAUA pasó a ocuparse de co-organizar la logística de la campaña en la Argentina que, además de los múltiples actos públicos, incluyó una serie de recepciones y entregas de títulos honoríficos a los candidatos por parte de instituciones y

28 Para las últimas elecciones presidenciales (2014) la comisión estuvo integrada por miembros de las comisiones de Transporte, Organización y Finanzas. Dos de sus miembros, ambos retornados al Uruguay que vivieron por tiempos variables en Argentina, se instalaron en Buenos Aires 21 días antes de las elecciones para ocuparse de las tareas ya mencionadas.

29 Es importante señalar que los vouchers constituyen un descuento adicional que corre por cuenta del FA y se suma al descuento que, para las fechas electorales, suelen estipular distintas empresas de transporte fluvial y terrestre. 
funcionarios del gobierno argentino, gestos que fueron entendidos como adhesiones políticas ${ }^{30}$.

La institucionalización del voto transnacional frenteamplista fue objeto de distintas lecturas al interior del FA en Uruguay. Si parte de su dirigencia vio en ella un "reconocimiento histórico" al esfuerzo desempeñado por el frenteamplismo en la Argentina desde tiempos de la dictadura, otros la consideraron un "gasto" de dinero y energía que, aunque podría no traducirse en un caudal de votos significativo, creían redituable en términos de relaciones y alianzas políticas en el orden regional. Esto último resultaba particularmente visible desde el año 2003 y el inicio de lo que fueron los tres períodos presidenciales del kirchnerismo en Argentina (2003-2015).

Como ya adelantamos, el arribo al gobierno argentino de Néstor Kirchner tensó diálogos y posiciones al interior del FAUA. Su militancia de base, tributaria de estrechas relaciones históricas con distintas fuerzas políticas argentinas, ahora alineadas en el "oficialismo" o la "oposición", se enfrentó en función de los recursos provistos para la campaña electoral ${ }^{31}$, pero también en torno de algunas de las políticas seguidas por el gobierno argentino en materia económica, de política exterior o derechos humanos. Pese a los esfuerzos de la Mesa Política del FAUA a la hora de convocar a "la unidad en la acción" y a "poner la mirada en Uruguay", lo cierto es que los alineamientos "kirchneristas" y "anti-kirchneristas" —que reeditaban la antinomia "peronismo"/"anti-peronismo" que muchos integrantes del FAUA experimentaron al momento de su arribo al país, tal como señalamos al comienzo del tercer acápite- derivaron en la desintegración de algunos comités de base y en el alejamiento de algunos de sus referentes, pero también en el surgimiento de nuevos liderazgos, especialmente entre las y los jóvenes frenteamplistas, ideológicamente y generacionalmente cercanos a las agrupaciones de jóvenes kirchneristas.

Vale señalar que la dirigencia montevideana y los candidatos del FA tampoco fueron ajenos a estas tensiones que se manifestaron

30 En su paso por Argentina, durante la campaña electoral de 2014, Tabaré Vázquez fue declarado "Huésped de Honor" de la ciudad de Buenos Aires y recibió el doctorado honoris causa por parte de la Universidad Nacional de Córdoba. En tanto, Danilo Astori, recibió el mismo título por parte de la Universidad Nacional de Misiones.

31 Esto es: el uso de instalaciones, la aceptación de donaciones y recursos económicos y el apoyo de sus estructuras militantes. 
en sus sucesivas visitas a Buenos Aires y en los encuentros sostenidos con políticos argentinos que, en algunos casos, pusieron en contradicción las relaciones institucionales de los sectores políticos a los que pertenecen, señalando así límites a la circulación transnacional posible ${ }^{32}$. Todo lo mencionado, en el marco del deterioro de la relación bilateral, contribuyó a que los últimos viajes electorales protagonizados por el frenteamplismo en la Argentina ingresen en el terreno de la "campaña sucia", visible en una serie de denuncias y desmentidas en la prensa de ambos países. Estas denuncias incluyeron: el ofrecimiento de pasajes gratuitos a quienes viajen a votar por el FA, la entrega de dinero por parte de una agrupación kirchnerista a la Mesa Política del FAUA para financiar el costo de algunos pasajes (El País 25/10/2009) y la cooperación en otros aspectos logísticos por parte de funcionarios del gobierno argentino, a los que se atribuyó el préstamo de uno de sus locales en Buenos Aires "para instalar un call-center gratuito desde donde se realizan entre 200 y 300 llamadas diarias para convocar a votar a los uruguayos residentes en Argentina" (La Nación 20/10/2014).

El FAUA intentó contener la desestabilización de la red creada por estas denuncias apelando a sus "nodos neutrales", especialmente a la hora de realizar actos y reuniones en Buenos Aires. De este modo, haciendo uso de la infraestructura de sindicatos, instituciones públicas (como las universidades nacionales) y distintas asociaciones de la sociedad civil, buscó demostrar su independencia de la trama política argentina. Pero lo cierto es que, en esta oportunidad, se enfrentó a un electorado que llegó al Uruguay fuertemente condicionado por las adhesiones o cuestionamientos al gobierno argentino. Por aquellos días, en los comités de base era habitual escuchar a quienes viajarían a votar al Uruguay justificar su voto al FA en su oposición "a Cristina” Fernández de Kirchner y la política hacia el Uruguay de su gobierno o, por el contrario, justificar su voto al FA en la adhesión al gobierno argentino, esperando que una tercera gestión del FA “copie”, por ejemplo, las políticas en materia de memoria y Derechos Humanos seguida por el kirchnerismo.

32 Esto quedó particularmente evidenciado en el acto de campaña que en 2014 tuvo lugar en la Casa "Patria Grande", uno de los puntos de encuentro más importantes de la juventud kirchnerista en Buenos Aires. Allí, los candidatos a legisladores por el MPP, el PSU y el PCU se reunieron con la colectividad uruguaya y la militancia argentina, desafiando con ello los alineamientos institucionales y las adhesiones locales de sus sectores políticos. 
Pasadas las últimas elecciones presidenciales, aquello que pareció desestabilizar el entramado transnacional frenteamplista atraviesa un proceso de recomposición, efecto de dos victorias electorales que el FAUA lee como antagónicas. Una de ellas es la victoria de Tabaré Vázquez (2014), que colaboró a la hora de serenar los ánimos de la militancia frenteamplista local y aseguró la continuidad de la gobernabilidad de la diáspora en Argentina; la segunda es la victoria de Mauricio Macri en las últimas elecciones presidenciales argentinas (2015). El reaseguro del tercer período de gobierno en Uruguay y el cambio de signo político en la Argentina ofician actualmente como refuerzo del compromiso frenteamplista local "contra el avance de la derecha en Latinoamérica" ${ }^{33}$. Esta consigna, que abrevó también en el proceso político abierto en Brasil, fue la empleada para movilizar el voto en la Argentina en ocasión de las últimas elecciones internas del FA. La percepción del FA como "un faro" como "última trinchera" en un contexto regional sumamente adverso para las fuerzas progresistas, podemos arriesgar, señala una nueva etapa de la red política transnacional que describimos hasta aquí, cuyos efectos sobre el voto Buquebus es una pregunta de respuesta abierta.

\section{PALABRAS FINALES}

Este artículo propuso explorar la producción y gestión de remesas políticas por parte del FAUA que, entre otras cuestiones, incluye la movilización del voto transnacional conocido por el término nativo "voto Buquebus"; aquel que, como describimos, implica el desplazamiento de dinero, ideas, valores, personas y sufragios de la Argentina al Uruguay ante cada jornada electoral en este último país, desde hace más de tres décadas. Para ello dimos cuenta de las transformaciones relativas a los actores que integran la red transnacional del frenteamplismo, sus canales de circulación, sus límites y su infraestructura.

33 Recientemente, en su página de Facebook, el FAUA afirmaba: "El 24 [de julio] no solo votamos por nuestro Frente Amplio, votamos CONTRA el avance de la derecha en Latinoamérica. Hoy, como nunca, Uruguay y el Frente Amplio deben ser un faro bien alto en defensa de la clase obrera." 
A partir de la reconstrucción del proceso político que dio origen a la militancia transnacional frenteamplista en la Argentina, la doble transición política que identificamos para ella y las coyunturas de (des)estabilización de su red (integrada por militantes políticos, dirigentes sociales y sindicales, funcionarios de gobierno, medios de comunicación y empresarios de ambos países), podemos ahora retomar algunas cuestiones señaladas por la literatura reseñada en el primer apartado de este artículo.

En principio, vimos que las prácticas políticas transnacionales del frenteamplismo en la Argentina no se reducen a un mero desplazamiento de votantes. Más bien, tal desplazamiento es posible en la medida en que existe una trama de relaciones y alianzas políticas históricas que atraviesan las fronteras territoriales, aportando aprendizajes, infraestructura y recursos materiales de diverso orden. En segunda instancia, vimos que, quienes movilizan esta red y este voto, no lo hacen - al menos no únicamente-como un signo de adhesión o preocupación por terceros que residen en el país, sino que disputan activamente las agendas de campaña, con la expectativa de una retribución que redunde en la gobernabilidad de la diáspora que integran. En tercer lugar, quisimos señalar que, si bien la referencia para la incorporación a la vida política del país de origen de los transmigrantes es el país de residencia, ésta se encuentra íntimamente asociada a cuestiones tales como las relaciones bilaterales o los alineamientos de las fuerzas políticas y los gobiernos de los países, cuyas historias confluyen en experiencias compartidas, tales como el terrorismo de Estado en los años 1970 y las transiciones democráticas en los años 1980. Posiblemente, entre otras cuestiones, esta sintonía contribuya a explicar la incorporación a la vida política transnacional no como el resultado o el efecto "reactivo" experimentado ante las dificultades y estigmatizaciones en el país de destino, sino como producto de una multiplicidad de diálogos y adscripciones identitarias de larga data, que tienden a demostrar la híper-integración de quienes componen la red. Dicho de otro modo, las prácticas políticas de la militancia transnacional frenteamplista en la Argentina parecen habilitadas por las intersecciones de los vínculos personales y las relaciones institucionales trabadas en una historia común; aquella que pone en juego desde políticas públicas y prácticas de Estado a transferencias financieras, ideológicas y pertenencias generacionales. Todo ello, con los consecuentes conflictos que supone, expresados en el 
paulatino proceso de institucionalización del voto transnacional, puede ayudarnos a comprender las transformaciones operadas sobre su principal remesa política, me refiero a la organización y gestión del voto transnacional. Este tipo de remesas, al igual que otras circulaciones transnacionales colectivas, no escapa a los condicionamientos o las oportunidades abiertas por las coyunturas. En la medida en que mutan las redes en que se sostienen, muta también su densidad, visibilidad y eficacia. De ahí que su abordaje diacrónico resulte crucial.

Finalmente, cabe señalar una última cuestión. Si bien este artículo desarrolla un estudio de caso pues, como señalamos al comienzo, las respuestas a los modos en que se producen y gestionan remesas políticas son necesariamente empíricas, entendemos que de lo expuesto puede derivarse una serie de contribuciones que lo exceden. En este sentido, esperamos que la traducción etnográfica de la propuesta analítica formulada por Boccagni et al. (2015) que intentamos hasta aquí contribuya a iluminar nuevas dimensiones e interrogantes que aporten a los estudios sobre prácticas políticas y ejercicio de la ciudadanía transnacional. Con este objetivo, podemos plantearnos una serie de interrogantes vinculados a las tensiones entre lealtades y oportunidades políticas en uno y otro país; a las diferencias entre las condiciones de posibilidad de este tipo de remesas en trayectorias migratorias regionales y aquellas que involucran a países cuyos grados de desarrollo son mucho más asimétricos; y, fundamentalmente, respecto de su potencia colectiva, creativa y democrática, en tiempos en que arrecian discursos y prácticas que enfatizan límites y fronteras tanto territoriales como simbólicas en el orden global.

\section{BIBLIOGRAFÍA}

Aguirre Bayley, M. (2007): Frente Amplio. Uno solo dentro y fuera del Uruguay en la Resistencia a la dictadura. Montevideo: Cauce.

BAUBÖCK, R. (2003): Towards a Political Theory of Migrant Transnationalism. International Migration Review, 3(37), 700-723.

Boccagni, P., Lafleur, J.-M. y Levitt, P. (2015): Transnational politics as cultural circulation: Toward a conceptual understanding of migrant political participation on the move. Mobilities, 11(3), 444-463. 
Calderón Chelius, L. (2010): Los superhéroes no existen. Los migrantes mexicanos ante las primeras elecciones en el exterior. México: Instituto Mora.

Collyer, M. (2013): A Geography of Extra-Territorial Citizenship: Explanations of External Voting. Migration Studies, 2(1), 55-72.

Crosa, Z. (2010): El voto de los uruguayos en el exterior. La extensión de los derechos políticos en el debate parlamentario. Encuentros Uruguayos, 3. Recuperado de http://www.encuru.fhuce.edu.uy/

EscribÁ, Á., Bermúdez, A. y Moraes, N. (2009): Migración y participación política. Estados, organizaciones y migrantes latinoamericanos en perspectiva local-transnacional. Córdoba: Consejo Superior de Investigaciones Científicas Instituto de Estudios Sociales de Andalucía.

Escobar, C., Arana, R. y McCann, J. (2014): Assessing Candidates at Home and Abroad: A Comparative Analysis of Colombian Expatriates in the 2010 Presidential Elections. Latin American Politics and Society, 56(2), 115-140.

Glick Schiller, N., Basch, L. y Szanton-Blanc, C. (1992): Towards a Definition of Transnationalism. Introductory Remarks and Research Questions. In: N. Glick Schiller; Basch, L. y Szanton-Blanc, C. (Eds.), Towards a Transnational Perspective on Migration: Race, Class, Ethnicity and Nationalism Reconsidered (pp. ix-xiv). New York: New York Academy of Sciences.

Goldring, L. (2004): Family and Collective Remittances to Mexico. Development and Change 35(4), pp. 799-840.

Halperin Donghi, T. (1994): La larga agonía de la Argentina peronista. Buenos Aires: Ariel.

Itzigsohn, J. y Villacrés, D. (2008): Migrant political transnationalism and the practice of democracy: Dominican external voting rights and Salvadoran home town associations. Ethnic \& Racial Studies 31(4), 664-86.

Itzigsohn, J. y SAucedo, S. (2002): “Immigrant Incorporation and Sociocultural Transnationalism. International Migration Review 36, 766-798.

Lacroix, T. (2014): Conceptualizing Transnational Engagements: A Structure and Agency Perspective on (Hometown) Transnationalism. International Migration Review, 48(3), 643-679.

LAfleur, J.-M. (2012): Transnacionalismo, Diáspora y Voto en el Exterior. En J.-M. Lafleur (Ed.), Diáspora y Voto en el Exterior. La Participación Política de los Emigrantes Bolivianos en las Elecciones de su País de Origen (pp. 15-38). Barcelona: CIDOB.

Merenson, S. (2013): Tras el voto Buquebus. Políticas, prácticas e interdependencias en la producción de la ciudadanía transnacional. Desarrollo Económico, 52(207-208), 285-306.

Merenson, S. (2015): El 'exilio' uruguayo en Argentina: intersecciones entre memoria, ciudadanía y democracia. European Review of Latin American and Caribbean Studies, 98, 49-67

Merenson, S. (2018): Political community and transnational citizenship: ethnographic perspectives on a heterogeneous articulation. Etnografica, 22(1), 149-167. 
Moraes, N. (2009): El voto que el alma no pronuncia: un análisis de las movilizaciones y los discursos sobre el derecho al voto de los uruguayos en el exterior. En Á. Escrivá, A., Bermúdez y N. Moraes (Eds.), Migración y participación política. Estados, organizaciones y migrantes latinoamericanos en perspectiva local-transnacional (pp. 103-123). Córdoba: Consejo Superior de Investigaciones Científicas Instituto de Estudios Sociales de Andalucía.

Murmis, M. y Portantiero, J. (1971): Estudios sobre los orígenes del peronismo. Buenos Aires: Siglo XXI.

Østergaard-Nielsen, E. (2003): Transnational Politics. Turks and Kurds in Germany. London: Routledge.

Porta, C. y Sempol, D. (2006): En Argentina: Algunas escenas posibles. En S. Dutreit Bielous (Ed.) El Uruguay del exilio. Gente circunstancias y escenarios (pp. 98-130). Montevideo: Trilce.

Portes, A. y Rumbaut, R. (1990): Immigrant America: A Portrait. California: University of California Press.

Portes, A., Guarnizo, L. y Landolt, P. (2003): El estudio del transnacionalismo: peligros latentes y promesas de un campo de investigación emergente. En A. Portes; L. Guarnizo y P. Landolt (Eds.), La globalización desde abajo: Transnacionalismo migrante y desarrollo. La experiencia de Estados Unidos y América Latina (pp. 15-44). México: Porrúa,.

Stuhldreher, A. (2013): Consideraciones en torno a al sufragio transnacional en el caso uruguayo. Temas de Antropología y migración, 5(1), 55-69.

TAsks, J. (2006): Migraciones internacionales en Uruguay: de pueblo trasplantado a diáspora vinculada. Theomai, 14(2), 139-156.

Waldinger, R. (2010): Rethinking transnationalism, EMPIRIA. Revista de Metodología de Ciencias Sociales, 19, 21-38.

Zeballos, M. (2010): Departamento 20: Emigrantes, exilados ou diaspóricos? Identidade narrativa, memória e hierarquias entre transmigrantes uruguaios". 27 Reunião Brasileira de Antropologia, Belém, Universidade Federal do Pará. 